PROFESI (Profesional Islam)

Media Publikasi Penelitian; 2017; Volume 15; No 1.

Website: ejournal.stikespku.ac.id

\title{
Efektivitas Pemberian Kombinasi Melon (Cucumis melo L) Semangka (Citrullus vulgaris) terhadap Tekanan Darah pada Lansia Hipertensi di Wilayah Kadipiro Surakarta
}

\author{
Anisah Lutfiasari ${ }^{1)}$, RetnoDewi Noviyanti ${ }^{2}$, Tuti Rahmawati ${ }^{3)}$ \\ 1),2),3) Program Studi S1 Gizi STIKES PKU Muhammadiyah Surakarta \\ lutfia.poena18@yahoo.co.id, retno.arvi2211@yahoo.com, tutirahmawati97@yahoo.com
}

\author{
Kata Kunci \\ Puding Melon \\ Semangka, \\ Jus Melon \\ Semangka, \\ Lansia, \\ Tekanan darah.
}

\begin{abstract}
Abstrak
Hipertensi merupakan salah satu penyakit degeneratif. Berdasarkan data Dinas Kesehatan Jawa Tengah (2013) sebanyak 554.771 kasus (67,57\%) dan berdasarkan data Dinas Kesehatan Kota Surakarta (2014) jumlah kasus hipertensi esensial tahun 2012 sebesar 14,9\%. Tujuan penelitian ini untuk mengetahui efektivitas pemberian kombinasi melon semangka terhadap tekanan darah pada lansia hipertensi di wilayah Kadipiro, Surakarta. Penelitian ini menggunakan desain penelitian yang bersifat Quasi Eksperiment design dengan rancangan pretest-posttest two groups design. Sampel penelitian sebanyak 54 orang dengan umur 50-70 tahun dengan menggunakan metode purposive sampling. Analisa data menggunakan uji wilxocon dan uji mann whitney. Hasil penelitian menunjukkan terdapat penurunan tekanan darah sistolik dan diastolik setelah perlakuan pada kedua kelompok yaitu puding melon semangka sebesar 22,78 $\pm 6,55 \mathrm{mmHg}$ dan $18,89 \pm 7,38 \mathrm{mmHg}$ dan jus melon semangka sebesar $21,85 \pm 7,61 \mathrm{mmHg}$ dan $10,93 \pm 5,72 \mathrm{mmHg}$. Tidak terdapat perbedaan tekanan darah sistolik dan diastolik sesudah perlakuan antara puding melon semangka dengan jus melon semangka $(p>0,05)$. Kesimpulannya adalah pemberian puding melon semangka dan jus melon semangka efektif terhadap penurunan tekanan darah sistolik dan diastolik $(p=0,000)$.
\end{abstract}

\section{The Effectiveness of Cucumis melo $\mathrm{L}$ and Citrullus vulgaris Combination on Blood Pressure of Hypertension Elderly In Kadipiro Region of Surakarta}

Keywords
Cucumis Melo l and
Citrullus Vulgaris
Pudding,
Cucumis Melo l and
Citrullus Vulgaris
Juice,
Elderly,
Blood Pressure.

\section{Abstract}

Hypertension is one of the degenerative diseases. Based on Central Java Health Service (2013) data of 554,771 cases (67,57\%) and based on data from Surakarta City Health Office (2014), the number of cases of essential hypertension in 2012 was $14.9 \%$. The purpose of this study is toknow the effectiveness of cucumis melo $l$ and citrullus vulgaris combination on blood pressure in hypertension elderly on Kadipiro, Surakarta.This research used Quasi Experiment design with pretest-posttest two groups design. The samples of research were 54 people with 50-70 years used purposive sampling method. Data analysis used wilxocon test and mann whitney test The results showedthere was a decrease in systolic and diastolic blood pressure after treatment in both groups that was cucumis melo $l$ and citrullus vulgaris pudding of 22,78 $\pm 6,55 \mathrm{mmHg}$ and 18,89 $\pm 7,38 \mathrm{mmHg}$ and cucumis melo $\mathrm{l}$ and citrullus vulgaris juice of 21,85 \pm 7,61 $\mathrm{mmHg}$ and 10,93 \pm 5,72 $\mathrm{mmHg}$. There was no difference in systolic and diastolic blood pressure after treatment between cucumis melo $l$ and citrullus vulgaris pudding with cucumis melo $l$ and citrullus vulgaris juice ( $p>0.05)$. Conclusion is the giving of cucumis melo $l$ and citrullus vulgaris pudding and cucumis melo land citrullus vulgaris juice is effective to decreased systolic and diastolic blood pressure $(p=0.000)$. 


\section{PENDAHULUAN}

Tekanan darah merupakan salah satu indikator penting dalam menjaga kesehatan tubuh karena tekanan darah yang tinggi (hipertensi) dalam jangka panjang akan menyebabkan perenggangan dinding arteri dan mengakibatkan pecahnya pembuluh darah.Hipertensi merupakan salah satu penyakit degeneratif.Pertambahan tekanan darah seiring bertambahnya umur, dari umur 55-74 tahun, lebih banyak perempuan dibanding laki-laki yang menderita hipertensi (Triyanto, 2014).

Menurut National Health and Nutrition Examination Survey (NHNES), insiden hipertensi di Amerika tahun 2010-2012 sekitar 39-51\%. Menurut WHO (2013) hipertensi tahun 2008 pada laki-laki sebesar $29,2 \%$ dan pada wanita sebesar 24,8\%. Berdasarkan Riskesdas (2013) prevalensi penyakit hipertensi di Indonesia mencapai 48,15\%. Berdasarkan data Dinas Kesehatan Jawa Tengah (2013)sebanyak 554.771 kasus $(67,57 \%)$ dan berdasarkan data Dinas Kesehatan Kota Surakarta (2014) jumlah kasus hipertensi esensial tahun 2012 sebesar 14,9\%.

Kejadian hipertensi dengan persentase yang cukup tinggi disebabkan oleh banyak faktor. Faktor-faktor yang dapat mempengaruhi terjadinya hipertensi terbagi menjadi 2 yaitu faktor yang dapat dikontrol seperti kebiasaan merokok, konsumsi alkohol, kurang aktivitas fisik, obesitas, stress, dan asupan natrium, dan faktor yang tidak dapat dikontrol seperti jenis kelamin, usia, keturunan (genetik), dan etnis. Kejadian hipertensi yang tinggi dapat menyebabkan komplikasi diantaranya penyakit jantung, penyakit ginjal, artherosclerosis, penyakit gagal ginjal, dan infark miokardium (Lewa dkk, 2010; Sutanto, 2010; Triyanto, 2014).

Penanganan hipertensi bertujuan untuk mengurangi morbiditas, mortalitas, dan mengontrol tekanan darah.Penanganan hipertensi dibagi menjadi 2 jenis yaitu terapi farmakologi yang menggunakan senyawa atau obat-obat yang bersifat anti hipertensi dan terapi non farmakologi yang memanfaatkan tanaman herbal (alami) (Pudiastuti, 2013).

Terapi farmakologis umumnya mempunyai efek samping yang serius. Salah satu efek samping yang ditimbulkan dari golongan diuretik yaitu mengakibatkan rendahnya kadar kalium dalam darah, terjadinya peningkatan kadar kolesterol Low Density Lipoprotein (LDL), trigliserida, asam urat, toleransi glukosa terganggu, dan disfungsi ereksi (Palmer dan Williams, 2007).

Alternatif pengobatan hipertensi untuk mencegah efek jangka panjang dari pengobatan farmakologi, dapat menggunakan pengobatan non farmakologi yaitu dengan memanfaatkan tanaman herbal. Tanaman herbal yang dapat dimanfaatkan untuk mengontrol atau menurunkan tekanan darah antara lain buah-buahan dan sayur-sayuran yang tinggi serat, vitamin dan mineral. Buah-buahan yang sering digunakan sebagai obat komplementer darah tinggi umumnya yang mengandung banyak air, kalium dan serat seperti buah melon dan semangka (Wulandari, 2011).

Buah melon dan semangka baik untuk penderita hipertensi. Buah melon memiliki kandungan kalium $379 \mathrm{mg} / 100 \mathrm{~g}$, serat $0,4 \mathrm{~g} / 100 \mathrm{~g}$, dan kadar air $93 \mathrm{ml} / 100 \mathrm{~g}$. Sedangkan buah semangka memiliki kandungan kalium 99,84 mg/100 g, serat $0,4 \mathrm{~g} / 100 \mathrm{~g}$ dan kadar air $93,4 \mathrm{ml} / 100 \mathrm{~g}$. Kandungan kalium, serat, dan air dalam buah melon dan semangka dapat menetralkan tekanan darah dan menjaga keseimbangan cairan dalam tubuh (Sudjianto dan Veronica, 2009; Pardede dan Muftri, 2011; Bimanteri, 2014).

Buah melon dan semangka mudah diperoleh dan harganya terjangkau untuk seluruh kalangan masyarakat. Cara mengkonsumsi buah-buahan tersebut selain dikonsumsi secara langsung dapat juga dikonsumsi dalam bentuk jus atau puding. Berbagai macam variasi bentuk dalam mengkonsumsi buah-buahan tersebut, akan meningkatkan daya tarik, nilai ekonomis yang lebih tinggi, meningkatkan kandungan zat gizi makanan yang akan dikonsumsi terutama serat, daya simpan lebih lama dan meningkatkan daya terima bagi lansia penderita hipertensi.

Berdasarkan latar belakang tersebut diatas peneliti tertarik untuk meneliti efektivitas pemberian kombinasimelon semangka terhadap tekanan darah pada lansia hipertensi di wilayah posyandu lansia Kadipiro, Surakarta.

\section{METODE PENELITIAN}

Penelitian ini menggunakan desain penelitian yang bersifat Quasi Eksperiment design dengan rancangan pretest-posttest two groups design. Penelitian ini dilakukan pada lansia de- 
ngan tekanan darah tinggi usia 50 - 70 tahun yang akan diberi perlakuan puding melon semangka dan jus melon semangka dan akan diukur tekanan darah sebelum dan sesudah perlakuan. Penelitian ini dilaksanakan pada bulan Februari dan bulan Juli 2017.

Pengambilan sampel diambil secara Purposive Sampling, dengan jumlah sampel 27 orang per kelompok. Pemberian puding melon semangka dan jus melon semangka selama 7 hari berturut-turut, sebanyak 1 gelas puding melon semangka (245 g) dan 1 gelas jus melon semangka (245 ml). Tekanan darah diukur sebelum dan sesudah perlakuan di masing-masing kelompok.

Data pengukuran tekanan darah sebelum dan sesudah pemberian puding melon semangka dan jus melon semangka ini akan diolah dan dianalisa menggunakan uji wilxocon. Data perbedaan dan data perbedaan selisih tekanan darah sistolik dan diastolik sebelum dan sesudah perlakuan antara puding melon semangka dan jus melon semangka ini akan diolah dan dianalisa menggunakan uji mann whitney.

\section{HASIL DAN PEMBAHASAN}

Karakteristik penelitian didasarkan pada wawancara yang dilakukan pada sampel penelitian. Wawancara ini bertujuan memperoleh karakteristik sampel yaitu meliputi umur, jenis kelamin dan asupan zat gizi.

Berdasarkan tabel 1, pada kelompok puding melon semangka menunjukkan bahwa sebagian besar sampel berusia pra lansia yaitu sejumlah 19 orang $(70,4 \%)$. Kelompok jus melon semangka menunjukkan bahwa sebagian besar sampel berusia pra lansia yaitu sejumlah 14 orang $(51,9 \%)$.

Tabel 1. Karakteristik Sampel Berdasarkan Umur pada Kelompok Puding dan Jus Melon Semangka

\begin{tabular}{cccc}
\hline $\begin{array}{c}\text { Kategori } \\
\text { Umur }\end{array}$ & $\mathrm{n}$ & $\%$ & $\begin{array}{c}x \pm \mathrm{SD} \\
\text { (tahun) }\end{array}$ \\
\hline \multicolumn{4}{c}{ Puding } \\
\hline melon semangka \\
\hline Pra lansia & 19 & 70,4 & $57,52 \pm 4,63$ \\
Lansia & 8 & 29,6 & \\
Jumlah & $\mathbf{2 7}$ & $\mathbf{1 0 0}$ \\
\hline \multicolumn{4}{c}{ Jus melon semangka } \\
\hline Pra lansia & 14 & 51.9 & $59,59 \pm 4,69$ \\
Lansia & 13 & 48,1 & \\
Jumlah & $\mathbf{2 7}$ & $\mathbf{1 0 0}$ \\
\hline
\end{tabular}

Hipertensi erat kaitannya dengan usia, semakin tinggi usia seseorang maka semakin tinggi tekanan darahnya. Arteri kehilangan elastisitasnya atau kelenturannya seiring bertambahnya usia, dengan bertambahnya usia maka risiko terjadinya hipertensi meningkat. Hipertensi bisa terjadi pada segala usia namun paling sering dijumpai pada orang berusia 35 tahun atau lebih. Hal ini disebabkan karena pada usia yang lebih tua, bagian-bagian organ seperti ginjal dan hati mulai menurun fungsinya (Lewa dkk, 2010).

Tabel 2. Karakteristik Sampel Berdasarkan Jenis Kelamin pada Kelompok Puding Melon Semangka dan Jus Melon Semangka

\begin{tabular}{ccc}
\hline Jenis Kelamin & $\mathrm{N}$ & $\%$ \\
\hline \multicolumn{2}{c}{ Puding melon semangka } & \\
\hline Laki-laki & 10 & 37 \\
Perempuan & 17 & 63 \\
Jumlah & $\mathbf{2 7}$ & $\mathbf{1 0 0}$ \\
\hline \multicolumn{2}{c}{ Jus melon semangka } & \\
\hline Laki-laki & 9 & 33,3 \\
Perempuan & 18 & 66,7 \\
Jumlah & $\mathbf{2 7}$ & $\mathbf{1 0 0}$ \\
\hline
\end{tabular}

Berdasarkan tabel 2, karakteristik sampel menurut jenis kelamin pada kelompok puding melon semangka sebagian besar adalah perempuan sebanyak 17 orang (63\%). Kelompok jus melon semangka sebagian besar adalah perempuan sebanyak 18 orang $(66,7 \%)$. Hasil tersebut menunjukkan bahwa proporsi perempuan lebih banyak menderita hipertensi dibandingkan lakilaki. Menurut hasil penelitian dari Anggraini, dkk (2009) didapatkan hasil lebih dari setengah penderita hipertensi berjenis kelamin wanita sekitar 56,5\%.

Tabel 3. Karakteristik Sampel Berdasarkan Asupan Zat Gizi pada Kelompok Puding Melon Semangka dan Kelompok Jus Melon Semangka

\begin{tabular}{|c|c|}
\hline Variabel & $x \pm$ SD \\
\hline \multicolumn{2}{|c|}{ Puding melon semangka } \\
\hline Asupan lemak (g) & $63,54+12,15$ \\
\hline Asupan natrium (mg) & $1053,62 \pm 193,96$ \\
\hline Asupan kalium (mg) & $2693,81+675,49$ \\
\hline \multicolumn{2}{|c|}{ Jus melon semangka } \\
\hline Asupan lemak (g) & $66,88 \pm 12,55$ \\
\hline Asupan natrium (mg) & $1084,95 \pm 231,17$ \\
\hline Asupan kalium (mg) & $2660,53+709,23$ \\
\hline
\end{tabular}


Berdasarkan tabel 3, hasil tersebut disbandingkan dengan $\mathrm{AKG}$, untuk asupan lemak pada usia 50-64 tahun dengan jenis kelamin laki-laki yaitu $65 \mathrm{~g}$ dan pada usia 65-80 tahun yaitu $53 \mathrm{~g}$, pada perempuan usia 50-64 tahun yaitu $53 \mathrm{~g}$ dan pada usia 65-80 tahun yaitu $43 \mathrm{~g}$. untuk asupan natrium pada usia 50-64 tahun dengan jenis kelamin laki-laki dan perempuan yaitu $1300 \mathrm{mg}$ dan pada usia 65-80 tahun yaitu $1200 \mathrm{mg}$. untuk asupan kalium pada usia 50-64 tahun dan usia 65-80 tahun dengan jenis kelamin laki-laki dan perempuan yaitu $4700 \mathrm{mg}$. Dapat disimpukan bahwa rata-rata asupan lemak berlebih, rata-rata asupan natrium berlebih, dan rata-rata asupan kalium kurang.

Konsumsi lemak yang berlebih dapat menyebabkan tekanan darah meningkat. Konsumsi lemak yang berlebihan akan meningkatkan kadar kolesterol dalam darah terutama kolesterol LDL dan akan tertimbun dalam tubuh. Timbunan lemak yang disebabkan oleh kolesterol akan menempel pada pembuluh darah yang lama kelamaan akan terbentuk plak. Terbentuknya plak dapat menyebabkan penyumbatan pembuluh darah atau artherosclerosis. Pembuluh darah yang terkena artherosclerosis akan berkurang elastisitasnya dan aliran darah keseluruh tubuh akan terganggu serta dapat memicu meningkatnya volume darah dan tekanan darah. Meningkatnya tekanan darah tersebut dapat mengakibatkan terjadinya hipertensi (Jansen, 2007).

Penelitian oleh Widyaningrum (2014) menunjukkan bahwa pada lansia terdapat hubungan antara konsumsi kalium dengan tekanan darah, penelitian ini sesuai dengan penelitian Anggara dan Prayitno (2013) menunjukkan bahwa kejadian hipertensi lebih banyak diderita oleh responden yang asupan kaliumnya tidak sering $(51,7 \%)$ daripada responden yang asupan kaliumnya sering (17,4\%).

Berdasarkan tabel 4, menunjukkan rata-rata nilai tekanan darah sistolik pada sampel sebelum diberikan puding melon semangka sebesar $160 \pm 13,08 \mathrm{mmHg}$, diastolik sebesar 95,15 \pm 7,74 $\mathrm{mmHg}$ dan sesudah perlakuan sebesar 137,22 $\pm 9,94 \mathrm{mmHg}$, diastolik sebesar 79,26+7,81 mmHg. Rata-rata nilai tekanan darah sistolik pada sampel sebelum diberikan jus melon semangka sebesar $156,11 \pm 8,70 \mathrm{mmHg}$, diastolik sebesar 94,07+4,39 mmHg. dan sesudah perlakuan sebesar $134,26 \pm 7,43 \mathrm{mmHg}$, diastolik sebesar
$83,15+3,96 \mathrm{mmHg}$. Berdasarkan hasil uji wilcoxon tekanan darah sistolik dan diastolik sebelum dan sesudah pemberian puding dan jus melon semangka didapatkan nilai $\mathrm{p}=0,000$ sehingga ada perbedaan hasil tekanan darah sistolik dan diastolik sebelum dan sesudah pemberian puding dan jus melon semangka.

Tabel 4.Tekanan Darah Sistolik dan Diastolik pada Sampel Sebelum dan Sesudah diberikan Puding dan Jus Melon Semangka

\begin{tabular}{|c|c|c|c|}
\hline $\begin{array}{c}\text { Tekanan } \\
\text { Darah }\end{array}$ & $\begin{array}{c}x \pm \text { SD } \\
(\mathrm{mmHg})\end{array}$ & $\mathbf{Z}$ & $\mathbf{p}^{*}$ \\
\hline \multicolumn{4}{|c|}{ Kelompok Perlakuan } \\
\hline \multicolumn{4}{|c|}{ Puding Melon Semangka } \\
\hline Sistolik & $160 \pm 13,08$ & & \\
\hline & & $\overline{-}, 589$ & 0,000 \\
\hline $\begin{array}{l}\text { Sistolik } \\
\text { Sesudah }\end{array}$ & $137,22 \pm 9,94$ & & \\
\hline $\begin{array}{l}\text { Diastolik } \\
\text { Sebelum }\end{array}$ & $95,15 \pm 7,74$ & & \\
\hline Diastolik & & $\begin{array}{c}- \\
4,642\end{array}$ & 0,000 \\
\hline Sesudah & $79,26 \pm 7,81$ & & \\
\hline \multicolumn{4}{|c|}{ Jus Melon Semangka } \\
\hline $\begin{array}{c}\text { Sistolik } \\
\text { Sebelum }\end{array}$ & $156,11 \pm 8,70$ & 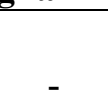 & \\
\hline $\begin{array}{l}\text { Sistolik } \\
\text { Sesudah }\end{array}$ & $134,26 \pm 7,43$ & 4,557 & 0,000 \\
\hline $\begin{array}{l}\text { Diastolik } \\
\text { Sebelum }\end{array}$ & $94,07 \pm 4,39$ & & \\
\hline $\begin{array}{c}\text { Diastolik } \\
\text { Sesudah }\end{array}$ & $83,15 \pm 3,96$ & $4, \overline{4} 19$ & 0,000 \\
\hline
\end{tabular}

Menurut Bambang dan Adriyani (2012), faktor risiko yang berperan untuk terjadinya hipertensi meliputi faktor risiko yang tidak dapat dikendalikan (mayor) dan faktor risiko yang dapat dikendalikan (minor).Faktor risiko yang tidak dapat dikendalikan (mayor) seperti keturunan (genetik), jenis kelami, ras, dan umur. Sedangkan faktor risiko yang dapat dikendalikan (minor) yaitu olahraga, makanan, alkohol, stress, kelebihan berat badan, kehamilan dan penggunaan pil kontrasepsi. 
Penelitian ini sesuai dengan penelitian yang telah dilakukan oleh Fridaini dan Sapardi (2013) yang menunjukkan bahwa ada pengaruh pemberian jus semangka (Cilitrus Vulgaris Schrad) terhadap tekanan darah pada lansia dengan riwayat hipertensi di Kota Padang. Penelitian ini juga sesuai dengan penelitian yang dilakukan oleh Mariani (2007) menunjukkan bahwa mengkonsumsi jus semangka dan jus melon berpengaruh terhadap penurunan tekanan darah sistolik maupun diastolik.

Berdasarkan tabel 5, uji mann whitney untuk tekanan darah sistolik sesudah perlakuan didapatkan nilai $\mathrm{p}=0,494$ sehingga tidak ada perbedaan tekanan darah sistolik sesudah perlakuan antara yang diberikan puding melon semangka dengan jus melon semangka. Berdasarkan uji mann whitney untuk tekanan darah diastolik sesudah perlakuan didapatkan nilai $\mathrm{p}=0,041$ sehingga ada perbedaan tekanan darah diastolik sesudah perlakuan antara yang diberikan puding melon semangka dengan jus melon semangka.

Tabel 5. Perbedaan Tekanan Darah Sistolik dan Diastolik Sesudah Perlakuan Antara Puding dan Jus Melon Semangka

\begin{tabular}{|c|c|c|}
\hline Variabel & $\begin{array}{c}x \pm \mathrm{SD} \\
(\mathrm{mmHg})\end{array}$ & $\mathbf{p}^{*}$ \\
\hline \multicolumn{3}{|c|}{ Tekanan darah sistolik sesudah perlakuan } \\
\hline $\begin{array}{l}\text { Sistolik puding } \\
\text { melon semangka }\end{array}$ & $137,22 \pm 9,94$ & \multirow{3}{*}{0,494} \\
\hline & & \\
\hline $\begin{array}{l}\text { Sistolik jus melon } \\
\text { semangka }\end{array}$ & $134,26 \pm 7,43$ & \\
\hline Variabel & $\begin{array}{c}x \pm \mathrm{SD} \\
(\mathrm{mmHg})\end{array}$ & $\mathbf{p}^{*}$ \\
\hline \multicolumn{3}{|c|}{ Tekanan darah diastolik sesudah perlakuan } \\
\hline $\begin{array}{l}\text { Diastolik puding } \\
\text { melon semangka }\end{array}$ & $79,26 \pm 7,81$ & \multirow{2}{*}{0,041} \\
\hline $\begin{array}{l}\text { Diastolik jus melon } \\
\text { semangka }\end{array}$ & $83,15 \pm 3,96$ & \\
\hline
\end{tabular}

Hal ini dikarenakan buah semangka dan buah melon yang digunakan dalam pembuatan puding dan jus memiliki berat yang sama yaitu untuk semangka $150 \mathrm{~g}$ dan melon $95 \mathrm{~g}$. Dalam buah semangka dan buah melon sama-sama memiliki kandungan zat gizi berupa kalium, banyak kandungan air, asam amino sitrulin, vitamin C dan vitamin A (Nisa, 2012).

Penelitian Figueroa (2006) dalam Nisa (2012) mengatakan bahwa kandungan asam amino semangka mampu meningkatkan fungsi arteri dan menurunkan tekanan darah pada aorta. Semangka dapat menurunkan tekanan darah tinggi karena mengandung potassium, vitamin $\mathrm{C}$, karbohidrat, likopen yang berfungsi untuk meningkatkan kerja jantung dan sitrulin yang mampu mendorong aliran darah ke seluruh bagian tubuh serta memberikan efek arfosidiak. Semangka mengandung vitamin $\mathrm{C}$ yang dapat meningkatkan kekebalan tubuh serta vitamin A yang dapat melawan infeksi.

Berdasarkan tabel 6, uji mann whitney untuk tekanan darah sistolik antara perlakuan yang diberikan puding melon semangka dengan jus melon semangka didapatkan nilai $\mathrm{p}=0,527$ sehingga tidak ada perbedaan selisih tekanan darah sistolik antara perlakuan yang diberikan puding melon semangka dengan jus melon semangka tetapi ada selisih ternyata untuk tekanan darah sistolikyaitu $0,93 \pm 1,06 \mathrm{mmHg}$. Berdasarkan uji mann whitney untuk tekanan darah diastolik antara perlakuan yang diberikan puding melon semangka dengan jus melon semangka didapatkan nilai $\mathrm{p}=0,000$ sehingga ada perbedaan selisih tekanan darah sistolik antara perlakuan yang diberikan puding melon semangka dengan jus melon semangkayaitu 7,96 \pm 1,66 mmHg.Selain itu kelompok puding melon semangka terdapat penambahan serat yang berasal dari agar-agar.

Tabel 6. Perbedaan Selisih Tekanan Darah Sistolik dan Diastolik Sesudah Perlakuan Antara Puding dan Jus Melon Semangka

\begin{tabular}{lcc}
\hline \multicolumn{1}{c}{ Variabel } & $\begin{array}{c}\boldsymbol{x} \pm \mathbf{S D} \\
(\mathbf{m m H g})\end{array}$ & $\mathbf{p}^{*}$ \\
\hline $\begin{array}{l}\text { Sistolik puding } \\
\text { melon semangka }\end{array}$ & $22,78 \pm 6,55$ & \\
$\begin{array}{l}\text { Sistolik jus melon } \\
\text { semangka }\end{array}$ & $21,85 \pm 7,61$ & 0,527 \\
$\begin{array}{l}\text { Diastolik puding } \\
\text { melon semangka }\end{array}$ & $18,89 \pm 7,38$ & \\
$\begin{array}{l}\text { Diastolik jus melon } \\
\text { semangka }\end{array}$ & $10,93 \pm 5,72$ & 0,000 \\
\hline
\end{tabular}


Menurut Dauche (2007), asupan serat dapat mengurangi kadar kolesterol yang bersirkulasi dalam plasma darah, karena serat dapat mencegah absorbsi kolesterol dalam usus, dan meningkatkan ekskresi asam empedu ke feses, sehingga meningkatkan perubahan kolesterol plasma menjadi asam empedu. Serat berkaitan dengan pencegahan terjadinya tekanan darah tinggi terutama jenis serat kasar (crude fiber).Dalam puding melon semangka terdapat kandungan serat yang berasal dari agar-agar dan buahnya.Penelitian yang dilakukan oleh Nuryanti (2014) menunjukkan bahwa dengan mengkonsumsi serat sebanyak 7 gram perhari dapat membantu menurunkan tekanan darah sistolik dan tekanan darah diastolik sebanyak 5 point.

\section{SIMPULAN}

1. Deskripsi tekanan darah sebelum dan sesudah perlakuan

a. Rata-rata tekanan darah sebelum perlakuan pada kelompok puding melon semangka sistolik sebesar $160,18 \mathrm{mmHg}$ dan diastolik sebesar 98,04 $\mathrm{mmHg}$.

b. Rata-rata tekanan darah sebelum perlakuan pada kelompok jus melon semangka sistolik sebesar $155,86 \mathrm{mmHg}$ dan diastolik sebesar 93,97 $\mathrm{mmHg}$.

c. Rata-rata tekanan darah sesudah perlakuan pada kelompok puding melon semangka sistolik sebesar 137,32 $\mathrm{mmHg}$ dan diastolik sebesar 79,64 mmHg.

d. Rata-rata tekanan darah sesudah perlakuan pada kelompok jus melon semangka sistolik sebesar $134,48 \mathrm{mmHg}$ dan diastolik sebesar $83,45 \mathrm{mmHg}$.

2. Pemberian puding dan jus melon semangka efektif terhadap penurunan tekanan darah sistolik maupun diastolik $(\mathrm{p}=0,000)$.

3. Perbedaan tekanan darah sistolik dan diastolik sebelum dan sesudah perlakuan

a. Tidak ada perbedaan tekanan darah sistolik sebelum perlakuan antara yang diberikan puding melon semangka dengan yang diberikan jus melon semangka $(p=0,410)$.

b. Ada perbedaan tekanan darah diastolik sebelum perlakuan antara yang diberikan puding melon semangka dengan yang diberikan jus melon semangka $(\mathrm{p}=0,042)$ c. Tidak ada perbedaan tekanan darah sistolik dan diastolik sesudah perlakuan antara yang diberikan puding melon semangka dengan yang diberikan jus melon semangka ( $\mathrm{p}>0,05)$.

4. Selisih tekanan darah sistolik antara puding melon semangka dengan jus melon semangka adalah $0,93 \pm 1,06 \mathrm{mmHg}$. Selisih tekanan darah diastolik adalah $7.96 \pm 1,66$ $\mathrm{mmHg}$.

\section{SARAN}

a. Perlu adanya sosialisasi mengenai manfaat buah melon dan buah semangka sebagai obat alami dalam upaya untuk mencegah dan mengatasi tekanan darah tinggi atau hipertensi disertai gaya hidup yang berkaitan dengan faktor-faktor risiko terjadinya hipertensi.

b. Perlu penelitian lebih lanjut terhadap bahan makanan sumber kalium lainnya dan komponen lain dalam bahan makanan yang diduga dapat mempengaruhi penurunan tekanan darah dengan waktu dan frekuensi perlakuan yang lebih lama.

\section{DAFTAR PUSTAKA}

Anggara, FDH dan Prayitno, N. 2013. Faktorfaktor yang Berhubungan dengan Tekanan Darah di Puskesmas Telaga Murni Cikarang Barat. Jurnal Ilmiah Kesehatan. 21-3.

Anggraini, A.D., Asputra, H., Siahaan.S.S., Situmorang, E., and Warren, A. 2009. Faktor-faktor yang Berhubungan dengan Kejadian Hipertensi pada Pasien yang Berobat di Poliklinik Dewasa Puskesmas Bangkinang. Makalah. Riau :FK UNRI.

Bambang, W dan Adriyani, M. 2012. Pengantar Gizi Masyarakat. Jakarta: Kencana Prenada Media Grup.

Bimanteri, Liling. 2014. Pengaruh Pemberian Jus Melon Terhadap Tekanan Darah Penderita Hipertensi di Modinan Banyuraden Sleman Yogyakarta. Skripsi. Yogyakarta: Program Studi Ilmu 
PROFESI (Profesional Islam)

Media Publikasi Penelitian; 2018; Volume 15; No 2.

Website: ejournal.stikespku.ac.id

Keperawatan STIKES 'Aisyiyah Yogyakarta.

Dauche. 2007. Dietary Pattern and Blood Pressure Change Over 5-y Follow-up in the SU.VI.MAX cohort. Am J Clin Nutr. $85: 1650-6$

Dinas Kesehatan Kota Surakarta.2014. Profil Kesehatan Kota Surakarta Tahun 2013. Surakarta: Dinas Kesehatan Kota Surakarta.

Dinas Kesehatan Provinsi Jawa Tengah. 2013. Buku Profil Kesehatan Provinsi Jawa Tengah Tahun 2012. Semarang: Dinas Kesehatan Provinsi Jawa Tengah.

Fridaini, N dan Sapardi, VS. 2013. Pengaruh Pemberian Jus Semangka (Cilitrus Vulgaris Schrad) Terhadap Penurunan Tekanan Darah Lansia dengan Riwayat Hipertensi di Kota Padang.Jurnal Ilmiah Kesehatan.

Jansen, S. 2007. Makanan Fungsional. Yogyakarta.

Lewa., Abdul, F., Dewa, P,P., \& Bening, R. 2010. Faktor-faktor Risiko Hipertensi Sistolik Terisolasi pada Lanjut Usia. Jurnal Berita Kedokteran Masyarakat. 26 (4): 12-17.

Mariani, Elis. 2007. Pengaruh Pemberian Jus Pepaya (Carica Papaya), Jus semangka (Citrullus Vulgaris) dan Jus Melon (Cucumis Melo) Terhadap Penurunan Tekanan Darah Sistolik dan Diastolik. Skripsi. Fakultas Kedokteran. Universitas Diponegoro Semarang.

Nisa, Intan. 2012. Ajaibnya Terapi Herbal Tumpas Penyakit Darah Tinggi. Jakarta: Dunia Sehat.

Nuryanti, Rita. 2014. Pengaruh Pemberian Puding Kacang Merah Vigna Angularis) Terhadap Kadar Glukosa Darah Puasa, Tekanan Darah dan Lingkar Pinggang Obesitas Hipertensi dan Non Hipertensi pada Remaja Putri. Skripsi. Fakultas Kedokteran. Universitas Diponegoro.
Palmer dan Williams. 2007. Introduce to Food Service.Edisi ke-11. New Jersey: Prentice Hall.

Pardede, Tuty Roida dan Sri Muftri D.S. 2011. Penetapan Kadar Kalium, Natrium dan Magnesium pada Semangka (Citrullus Vulgaris, Schard) Daging Buah Berwarna Kuning dan Merah Secara Spektofotometri Serapan Atom. Jurnal Darma Agung.

Pudiastuti, RD. 2013. Penyakit-penyakit Mematikan. Yogyakarta: Nuha Medika.

Riskesdas. 2013. Riset Kesehatan Dasar 2012. Jakarta: Kementerian Kesehatan Republik Indonesia.

Sudjianto dan Veronica, K. 2009. Studi Pemulsaan dan Dosis NPK pada Hasil Buah Melon.Jurusan Sains dan Teknologi 2.

Sutanto. 2010. Hubungan Asupan Zat Gizi dan Aktivitas Fisik Terhadap Diabetes Mellitus Tipe 2 pada Pegawai Negeri Sipil Dinas Kesehatan Provinsi Kalimantan Timur. Skripsi. Universitas Jember.

Triyanto, Endang. 2014. Pelayanan Keperawatan Bagi Penderita Hipertensi Secara Terpadu. Yogyakarta: Graha Ilmu.

WHO. 2013. World Health Statistic 2008. Geneva : WHO Press.

Widyaningrum, A.T. 2014. Hubungan Asupan Natrium, Kalium, Magnesium dan Status Gizi dengan Tekanan Darah pada Lansia di Kelurahan Makamhaji Kecamatan Kartasura. Skripsi. Surakarta: Prodi Gizi Fakultas Ilmu Kesehatan. Universitas Muhammadiyah Surakarta.

Wulandari, Ayu Fitri Sekar. 2011. Kejadian dan Tingkat Depresi pada Lanjut Usia Studi Perbandingan di Panti Wreda dan Komunitas. Skripsi. Semarang: Fakultas Kedokteran Universitas Diponegoro 